\title{
Histórias de vida como fato museal tratado pelo Design da Informação na Curadoria Digital no Museu da Pessoa
}

\author{
Maria José Vicentini Jorente \\ Karen Kahn \\ Universidade Estadual Paulista “Júlio de Mesquita Filho” - UNESP, Brasil
}

REVIEW

\begin{abstract}
Resumo
O artigo baseia-se em pesquisa que busca verificar o papel do Design da Informação na Curadoria Digital do Museu da Pessoa na Web 2.0 e o seu objetivo é refletir sobre o seu fato museal, histórias de vida. Em tempos de custódia ampliada, o Museu da Pessoa destaca-se como sistema memorial dinâmico, interativo e colaborativo. Previsto em e para Curadoria Digital, o Design da Informação é meio facilitador de indexações de conteúdo informacional bem como da organização gráfica desses conteúdos, tanto top-down quanto bottom-up, a fim de que sujeitos não apenas reconheçam histórias de vida como um objeto cultural tangível, um fato museal, mas também para que se reconheçam enquanto seres humanos atuantes no processo informacional, reforçando vínculos identitários por meio de Tecnologias de Informação e Comunicação (TIC). A necessidade de se conhecer novos meios e estratégias para a Curadoria Digital em instituições museológicas no âmbito da Ciência da Informação justifica esse artigo com o qual espera-se favorecer a compreensão do Museu como um modelo para a preservação e interação com histórias de vida, narrativas autobiográficas, entendidas, neste contexto, como bens culturais e patrimônio memorial. Como resultado do estudo, verifica-se que, por meio de suas metodologias, e em convergência com a Ciência da Informação, o Design da Informação cria um simulacro de museu online, em fluxo e ubíquo, bem como condições para uma Curadoria Digital (top-down), tendo em vista a representação e a preservação de objetos culturais digitais, assim como seu acesso, aos agentes informacionais da instituição e aos internautas (bottom-up), interativamente, na Web 2.0 .
\end{abstract}

Palavras-chave

Brasil; Curadoria digital; Design da informação; Fato museal; Informação e tecnologia; Museu da Pessoa.

\section{Stories of life as a museum fact treated by the design of the Information in the digital curatorship in the Museu da Pessoa}

\begin{abstract}
The article is based on research that seeks to verify the role of Information Design in the Digital Curation of Museu da Pessoa in Web 2.0, and the objective is to reflect on its museological fact, life stories. In times of extended custody, Museu da Pessoa stands out as a dynamic, interactive and collaborative memorial system. Planned in and for Digital Curation, Information Design facilitates the indexing of informational content as well as the graphic organization of such content, both top-down and bottom-up, so that subjects not only recognize life stories as an object, but also recognize them as human beings who are active in the information process, reinforcing identity links through Information and Communication Technologies (ICT). The need to acknowledge new means and strategies for Digital Curation in museum institutions in the scope of Information Science justifies this article with which we expect to enhance the understanding of the Museum as a model for the preservation and interaction with life stories, autobiographical narratives, understood in this context as cultural goods and memory heritage. As a result of the study, it is verified that, through its methodologies and in convergence with Information Science, Information Design creates a simulacrum of online, flowing and ubiquitous museum in addition to the conditions for Digital Curation (top -down) aiming at the representation and preservation of digital cultural objects, as well as their access to the institution's information agents and bottom-up users, interactively, in the Web 2.0.
\end{abstract}

Keywords

Brasil; Digital curation; Information and technology; Information design; Museological fact; Museu da Pessoa. 


\section{Introdução}

Na pós-modernidade, museus, arquivos e bibliotecas, tradicionais instituições de informação e memória buscam ser ambientes convidativos e dialógicos ao promover trocas bilaterais e interativas entre seu acervo e diferentes públicos. Por meio de mediações culturais institucionais procuram, assim, fortalecer vínculos identitários. Vivências elaboradas por equipes de profissionais da informação são oferecidas por meio de visitas orientadas, cursos, oficinas, palestras e workshops em situações presenciais.

A vocação dessas instituições nem sempre foi dialógica: no anterior paradigma custodial, historicista, patrimonialista e tecnicista, a ideia da preservação e da guarda da memória teve sempre uma preferência em detrimento à ideia do acesso (RIBEIRO, 2010). Neste sentido, Araújo lembra-nos que, "na esteira do positivismo, foram privilegiadas as técnicas de tratamento (descrição, inventário, classificação, conservação, exposição) dos acervos custodiados nas instituições" (ARAÚJO, 2014, p.6).

Salvaguardar acervos deu, durante muito tempo, ao profissional destas instituições, um estatuto de técnico especializado e erudito, tornando-o um curador indispensável na preservação da informação, típico de paradigmas da Ciência da Informação $(\mathrm{Cl})$ anteriores ao pós-custodial, a saber: o paradigma físico e o paradigma cognitivo, segundo Rafael Capurro (CAPURRO, 2003).

Tal profissional tinha centralizado em si as técnicas que geravam os instrumentos de acesso a informações, dificultando, por vezes, a vida dos que buscavam por informações, ou seja: poderiam "disponibilizar em nome do direito à informação ou guardar a sete chaves em nome da privacidade dos cidadãos ou dos interesses do Estado". (RIBEIRO, 2010, p. 64).

Novos recursos que requerem saberes e fazeres diversos podem, no entanto, alterar essa antiga vocação institucional ao proporcionar experiências diversas em Arquivos, Bibliotecas e Museus. Entre tais recursos estão as Tecnologias de Informação e Comunicação (TIC) que possibilitam experiências de uma natureza diversa da presencial mediante busca de informação e conhecimento, proporcionando vivências complementares aos sujeitos que adentam simulacros digitais de tradicionais instituições de informação e cultura.

No caso das instituições museológicas, por exemplo, percorreu-se um longo caminho, partindo dos gabinetes particulares de curiosidades (séculos XV e XVI) pertencentes à nobreza e à realeza que se abriam a público restrito, passando pelos museus modernos (séculos XVIII e XIX), chegando ao museu contemporâneo. Em ambientes digitais, ou websites de museus, sistemas informacionais podem convergir em si, por meio de um Design da Informação (DI) pensado para o acesso (inclusive como estratégia de preservação da informação), e com outros sistemas de informação que interoperem em suas interfaces - com o intuito de promover reflexões e conversações (WAGENSBERG, 2005) com internautas, a partir e além de seu objeto. No contexto, entende-se o DI como a arte e a ciência de preparar informação a ser utilizada por pessoas de modo eficaz, tornando a comunicação eficiente por meio de palavras e imagens, entre outros meios convencionais ou digitais. (JACOBSON, 1999)

De acordo com Ribeiro (2010), o fenômeno da explosão informacional do pós-guerra inaugurou um novo paradigma, pós-custodial, ou de custódia ampliada que, convivendo com teorias e práticas de paradigmas anteriores, responde aos novos desafios aos ambientes digitais como: criação, organização, armazenamento, recuperação e compartilhamento de informação. Neste sentido, e ainda segundo Ribeiro (2010), a Internet revoluciona e instaura "o reordenamento possível para os serviços de informação e para os comportamentos de mediadores [...] em especial, os info-incluídos e os born digital ou nativos da Internet” (RIBEIRO, 2010, p. 68). Conforme Ribeiro (2010), os born digital1 seriam pessoas nascidas após 1989, na conjuntura de uma rede digital na Era da Informação.

Nesse contexto, destaca-se, no presente artigo, ações de Curadoria Digital (CD) que podem ser desenvolvidas por profissionais da informação atuantes em equipes multidisciplinares, com base em conhecimentos epistemológicos e técnicos da $\mathrm{Cl}$ e do $\mathrm{DI}$, entre outros, a fim de preverem convergências de linguagens que permitam interoperabilidades entre sistemas, estabelecendo desígnios em plataformas digitais customizáveis como, por exemplo, a ambiência virtual do Museu da Pessoa2. Para Sayão e Sales (2012, p.184), ainda que CD seja um conceito em evolução, pode-se definir o processo como um modo ativo de gestão e preservação de 
objetos digitais para que se atenda necessidades informacionais de gerações futuras. Segundo os autores, entre as metodologias utilizadas pela $C D$, estão os processos de arquivamento digital e de preservação digital, bem como a aplicação de metodologias para a criação e gestão de dados de qualidade para a sua valorização, potencializando seu uso e reuso.

A polissemia do termo design, a partir de sua raiz romana designare, permite, dessa maneira, pensar a área "não apenas como desenho e recurso projetual, mas também como um ato designador, ou seja, como aquilo que determina, em nosso contexto, a apresentação da informação museal em interfaces de interação (UX). (KAHN e JORENTE, 2016). Entre os recuros de DI, incluem-se modos de classificação e indexação, vocabulário controlado, ontologias, tesauros, taxonomias, cauda longa que podem contribuir para uma mediação entre pessoas em interfaces de interação em ambiência digital, pois favorecerão a busca, a recuperação e o acesso a informações na Web 2.0.

Buscou-se, dessa maneira, uma revisão bibliográfica para a compreensão do objeto deste estudo, assim como de conceitos e teorias que possam dar suporte a reflexões e conexões multi e transdisciplinares. Quanto a sua metodologia, partiu-se de pesquisa descritiva, a fim de sistematizar conhecimentos sobre recursos de DI na CD de um museu paradigmático, que constitui objeto de pesquisa de uma das autoras, o MP. Por meio de estudo histórico da instituição (dimensões epistemológica e contextual); revisão bibliográfica e documental (dimensões ética, política e teórica); participação indireta em observação planejada em ambiente digital, periódicos acadêmicos, teses e dissertações, entre outras fontes para a formação de um quadro de análise (dimensões técnica e morfológica), constituíram- se pilares sobre os quais se estrutura o trabalho que segue. $\mathrm{O}$ estudo e o artigo são justificados pela necessidade de se conhecer novas formatações para a CD no âmbito da Cl. Como resultado, espera-se a compreensão de modelo para a preservação e interação com memórias, entendidas como Patrimônio da Humanidade.

\section{Museu da Pessoa como tecnologia social}

Do ponto de vista político, a criação de um museu como o MP, que abriga como acervo histórias dos esquecidos, com base na premissa da democratização da informação, tornou-se possível devido ao alargamento da noção de história e de patrimônio e também devido à própria redefinição do papel dos museus na sociedade (HENRIQUES, 2004, p. 77).

Verifica-se em estudo histórico que o MP já era considerado virtual antes mesmo do advento da Internet, e que questões técnicas e tecnológicas, como as que se interligam a conceitos relacionados a patrimônio cultural e mediação institucional, entre outras, foram as perspectivas sobre as quais o MP se ergueu, em 1991, na cidade de São Paulo. Ainda conforme Henriques (2004), um museu virtual é o que possibilitaria a interação entre pessoas e determinado patrimônio de forma virtual, sem deslocamento em espaços museográficos tradicionais. Assim, a autora afirma que a criação de um museu de histórias de vida quase que pressupõe a criação de um museu virtual, uma vez que é impossível musealizar pessoas, no sentido tradicional do termo, tal como musealizamos objetos (HENRIQUES, 2004, p.66). Deste modo, apoiado sobre princípios políticos e éticos como a manutenção da memória e do patrimônio cultural, inclusão social e acesso a bens culturais e a espaços socializados, presenciais ou virtuais, o MP desenvolveu-se tendo, como missão3, ser um museu aberto e colaborativo que transforme as histórias de vida de toda e qualquer pessoa em fonte de conhecimento, compreensão e conexão entre pessoas e povos, um legado diferenciado da história do país, que prioriza o desejo de transformação cultural e social, implicando na construção de uma massa crítica suficientemente grande para garantir a sustentabilidade da ideia e de sua ampliação em inúmeros segmentos e espaços sociais.

Em estudo planejado no Portal do MP, observa-se que o seu marco histórico foi em dezembro de 1991, mas que apenas em 1997 percebeu-se a Internet, utilizada desde o ano anterior, como potencial de mudança dos paradigmas de acesso e participação, possibilitando novos modos do registro de memórias. A nova versão do site do Museu possibilitou uma maior interacção com os utilizadores (HENRIQUES, 2004, p. 95). Neste sentido, observa-se que a nova ambiência do MP nasceu da necessidade de um espaço para o registro e compartilhamento de memórias, com foco no acesso à informação, ainda que na Web 1.0. Não somente as memórias das pessoas famosas, que costumam ter espaço garantido na história oficial. A musealização de 
histórias das pessoas anônimas, sistematicamente excluídas da historiografia e mídias tradicionais, como jornais e televisão, pretende o resgate de valores e o cultivo de patrimônios para a construção de uma nova oralidade (SEVCENKO, 2005, p.46).

Em 1996, quando do primeiro ambiente digital do MP na Web 1.0, inevitavelmente reproduziu-se a lógica do fluxo de informação, característica dos modelos (DI) impressos em papel, uma vez que o esforço inicial foi o de colocar as memórias na primeira interface digital que se caracterizava por uma única página que continha uma única história de vida, substituída por membro da equipe do MP semanalmente. Nota-se que em ambiência Web 1.0, o MP já lança mão de recursos do DI para a sua limitada CD de sistemas memoriais. Destaca-se ainda que, naquele período, para o Projeto Conte sua História, memórias pessoais eram enviadas por e-mail, pelos internautas, e colocadas no ar, via programação HTML, por profissional da informação do Museu. Conforme o Portal, nos anos noventa, em que menos de vinte por cento da população brasileira tinha acesso à Internet, internautas visitantes do MP começaram a ter suas memórias publicadas - apesar do país não possuir uma tradição em cultura escrita - dando início ao projeto colaborativo de construção de uma memória coletiva e democrática. Para Henriques, a memória tem origem na sociedade, uma vez que nossas lembranças relacionam-se ao conjunto de noções de um grupo (HENRIQUES, 2004, p.16).

Ainda, segundo o Portal do MP, entre 2009 e 2016, a publicação Tecnologia Social da Memória4 foi utilizada por cerca de 1300 organizações e escolas. Entre outros objetivos, a tecnologia destinou-se também a apoiar discussões conceituais sobre o que é um roteiro, uma história de vida; e sobre ações como coleta de depoimentos e entrevistas, entre outros. Acrescenta-se que, a partir do modelo do MP brasileiro, desenvolveram-se três núcleos internacionais: um na Universidade do Minho, Portugal (1999), um na Universidade de Indianna, EUA (2000) e, finalmente, um terceiro no Centro de História de Montreal, Canadá (2003) que, embora autônomos, interligam-se pela Tecnologia Social da Memória e por objetivos comuns.

Observa-se, entretanto, que diferentemente do original nacional, as iniciativas de Portugal, dos EUA e do Canadá relacionam-se ao universo acadêmico em instituições de ensino locais: Departamento de Informática da Universidade do Minho, Departamento de Telecomunicações da Universidade de Indianna e Centre de Francophonie de las Amérique, em Montreal. Segundo o Prof. Dr. Rangel Henriques (Departamento de Informática da Universidade do Minho, Portugal, que reúne e dissemina o legado cultural entre sujeitos, principalmente por meios eletrônicos) em capítulo da publicação História Falada5 (PEREIRA e WORCMAN, 2005)

\footnotetext{
O trabalho do Núcleo Português do Museu da Pessoa partiu de um grupo de informáticos da Universidade do Minho, que enxergaram nas histórias de vida, uma chance de aplicar sua tecnologia em algo extremamente importante e útil para os outros. Contamos com a ajuda do Departamento de Comunicação Social para fazer as entrevistas, a transcrição e a edição dos depoimentos, pois certamente não é a nossa especialidade (HENRIQUES, in História Falada, 2005, p. 144).
}

A afirmação de Rangel Henriques ratifica a ideia de que, mesmo que tais núcleos tenham se desenvolvido fora de ambiências tradicionais de museus, e dentro da academia, eles estão abrigados em áreas que estabelecem relações disciplinares com a $\mathrm{Cl}$. Nota-se, porém, que as interfaces digitais dos núcleos dos Museus das Pessoas ainda não estão atualizadas na Web 2.0 para uma possível comparação entre curadoria e design. Neste sentido, desejada rede internacional com sistemas convergentes e padrões interoperantes, tendo em vista a preservação e o acesso a informações por meio de Curadoria Digital (SAYÃO e SALES, 2012) ainda não se concretizou.

\section{Memória como fato museal}

Epistemologicamente, memórias e histórias de vidas foram definidas como acervo do MP, objeto deste estudo, a saber um museu híbrido ou virtual ${ }^{6}$ resultante de uma mescla de fazeres oriundos de áreas do conhecimento multi e transdisciplinares, como Cl, Ciência da Computação, Museologia, História Oral (THOMPSON, 1992), Design, entre outras.

Segundo Rússio, 
[...] o que caracteriza um museu é a intenção com que foi criado, e o reconhecimento público (o mais amplo possível) de que é efetivamente um museu, isto é, uma autêntica instituição. O museu é o local do fato "museal"; mas para que esse fato se verifique com toda a sua força, é necessário "musealizar" os objetos (os objetos materiais tanto quanto os objetos-conceito) (RÚSSIO, in BRUNO 2010, p. 125).

Ao inserir a importância do reconhecimento por parte do público na seleção e na musealização de objetos, a autora destaca uma forma conversacional de encarar o papel dos museus, diferente da que Ribeiro (2010) apresenta ao se referir às mediações institucionais, características do paradigma custodial.

Na mesma direção, em O objeto de estudo da museologia (MENSCH, 1994), o pesquisador holandês Peter Van Mensch, sistematiza o percurso da Museologia em busca de autonomia como área de conhecimento e elenca os diversos entendimentos acerca do objeto de seu estudo, que inclui abordagens focadas em diferentes aspectos: no museu, em sua função, no objeto e sua musealização e, finalmente, na relação entre os sujeitos e sua realidade. $\mathrm{O}$ entendimento de que pessoas, frente à realidade, selecionam objetos originais para inseri-los em uma nova realidade, com o intuito de preservá-los, destaca a intenção cognitiva da Museologia que contribui para o desenvolvimento teórico sobre a dita musealidade e sobre o valor da informação como coisa ou fato museal, fruto da relação. Segundo Rússio (2010, p.123), "é na relação profunda entre Homem e objeto que surge a noção de fato museal”, pois já não se trata de um objeto com potencial, a priori, musealizável, mas o que ele representa simbolicamente para um determinado grupo. Necessariamente portador de protocolos identitários e valor simbólico, o fato museal pode ser entendido como um acontecimento ou uma evidência museal. Neste sentido, coloca-se em relação não apenas o sujeito (conhecedor) e o objeto (a ser admirado e conhecido por ser parte da realidade humana), mas também o contexto institucional, o cenário em que tal relação se estabelece. Será justamente nesta relação que se evidenciará, ou não, o fato museal.

Ao pensar o Museu como um campo de estudo da sociedade - e não dos objetos e das instituições, Rússio dá importante passo ao entender o Museu como um espaço para preservação de valores simbólicos. Para que isto ocorra, a autora destaca a necessidade de políticas públicas que incentivem a educação patrimonial, a fim de que protocolos reconhecíveis e apreciáveis possam ser apropriados pela sociedade, uma vez que o feedback é fundamental para a manutenção de sistemas dinâmicos.

Observa-se que o cenário, ou simulacro da vida, propício a tais relações entre sujeitos e realidade, é também um constructo cultural que se propõe a ser um local para a promoção de conversações e reflexões sobre transformações no tempo por meio de sentidos.

Para o estudo em tela, adotou-se o conceito de informação como coisa de Buckland (1991), uma evidência ou entidade tangível, representável e recuperável e que, no MP, tem a finalidade última de estreitar vínculos indentitários entre sujeitos, com vistas a manutenção de um bem cultural maior: a humanidade. Entendeu-se que tal metáfora pode ser apreendida ao se observar a ambiência digital do MP - a priori, um registro de memória ou uma coleção delas, não existe publicamente, é uma virtualidade intangível. Apenas a partir de sua representação, histórias de vida são narradas, representadas, tornando-se evidências: simulacros informacionais tangíveis que testemunham um modo de ser e fazer de um tempo a partir de uma plataforma ${ }^{7} \mathrm{e}$ sua Curadoria Digital.

A título de ilustração de simulacro e evidências tangíveis, apresenta-se a seguir um exemplo da introdução de recursos do DI na Curadoria Digital do MP, observada na dissertação de mestrado Sistema para indexação e visualização de depoimentos de história oral - O caso do Museu da Pessoa de Herzog ${ }^{8}$ (2014). Na tela captada, o autor destaca um projeto gerido na base dgura 1e dados do sistema memorial desenvolvida no Content Management System (CMS) Apache Shiro 1.0. Tal interface administrativa destina-se à CD de conteúdos informacionais do Museu e é gerida por seus agentes para criação, registro, armazenamento, disseminação, uso e reuso de informações, entre outras etapas referentes ao ciclo de vida da informação. A Figura 1 refere-se à parte superior da página administrativa Principal em que se observa um DI projetado para o desenvolvimento de projetos que envolvem a História Oral. Na tela, verifica-se a seguinte seleção de entidades realizada pelo Super Administrador Herzog: Projetos, Histórias, Pessoas e Vídeos (HERZOG, 2014). 


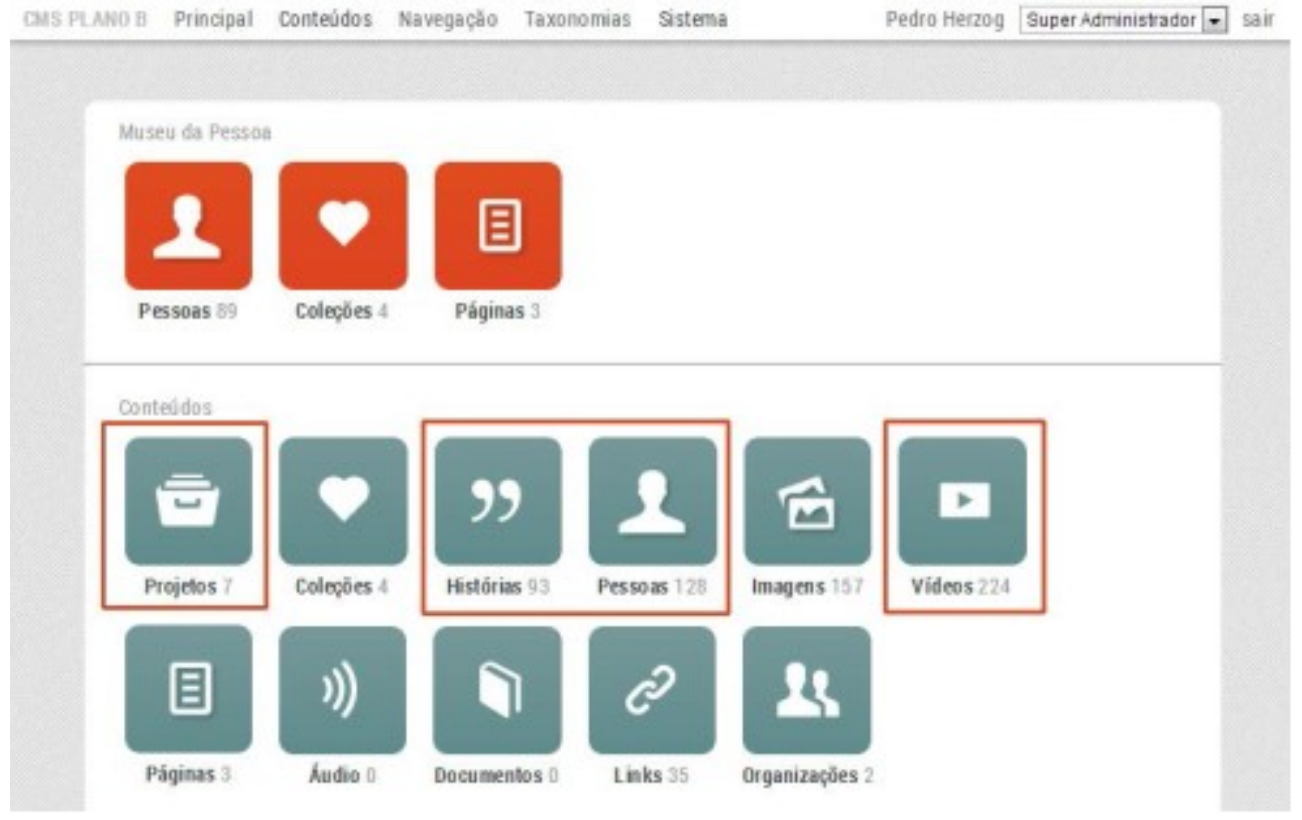

Fonte: HERZOG, 2014, p 50.

$\mathrm{Na}$ ambiência digital do MP, memórias evocam seu valor testemunhal que se converte no próprio valor do objeto ressignificado, uma vez que o seu DI, ao verter linguagens, opera um tipo de tradução intersemiótica (PLAZA, 2003), transcriando signos e significados da representação da informação em busca de sentidos. Importante ressaltar que, em resposta a um determinado DI, nesta nova ambiência tecnológica do fazer, um novo indivíduo também é moldado ao reagir de modo aperceptivo ao seu constructo, sendo criador e também criatura no sistema complexo do qual emerge. Nesta moldura, informações-objetos-coisas tornam-se evidências metalinguísticas epistemologicamente musealizadas em um cenário de trilhas reconhecíveis que preservam valores identitários não apenas em interfaces de interação, mas em várias camadas do hipertexto; refletindo em camadas invisíveis, por meio de convergência de linguagens e interoperabilidades (CD), o próprio ser humano que chega à contemporaneidade interagindo em ambiências digitais em busca de informação, conhecimento e reconhecimento. Considerando-se a representação de memórias como um fato museal tangível, a CD do MP, da qual tratar-se á a seguir, é desenvolvida por equipe multidisciplinar e, entre outros, cria simulacros top-down facilitadores de uma cultura de protagonismo e compartilhamento bottom-up de informações.

\section{Design da Informação e Curadoria Digital}

Como os museus em geral, o MP pode ser entendido com um ato cultural em que se redesenha uma realidade em ambiência simulada. Em particular, o seu ambiente ou cenário é previsto por meio de recursos de DI pela e para a Curadoria Digital. Observa-se que a representação do objeto terá o seu valor atrelado diretamente à eficácia do seu DI, ou seja, à capacidade metalinguística de falar de si, remeter a protocolos e narrar a si próprio enquanto representação, evidência traduzida, em última instância, de zeros e uns (JOHNSON, 2001). Esta é uma possível resposta sobre a importância e o papel do DI na multidisciplinar Curadoria Digital do MP. Vale novamente salientar que, além atuar em interfaces de interação, a Curadoria Digital, de forma menos aparente, atua em todas as camadas do sistema, sendo o DI um recurso designador de interfaces na plataforma.

Segundo o Digital Curation Centre (DCC), Curadoria Digital é um processo que envolve a manutenção e a preservação de dados digitais ao longo de seu ciclo de vida, tendo em vista maior acesso e a longo prazo. Neste sentido, minimizar o risco de obsolescência digital agrega valor às informações que, armazenadas em repositórios digitais confiáveis, poderão ser acessadas, usadas e reusadas. No MP, o trabalho realizado em equipe multidisciplinar para desenvolvimento do processo de Curadoria Digital projetado para suas necessidades comunicacionais de seu conteúdo informacional envolve a concepção e a criação de objetos digitais, incluindo métodos para captura de dados e opções para seu armazenamento. Assim, investiga o papel da organização da informação (DI) nesta e nas demais etapas do processo de CD. 
No paradigma pós-custodial que se insere no panorama da complexidade, sistemas memoriais, ao repensaremse na Web 2.0, sem uma ordem absoluta e na perspectiva de uma lógica que pode comportar vazios (MORIN, 2000), tradicionais instituições de informação devem lançar um novo olhar sobre si a fim de se reestruturarem e se reorganizarem em ambiências nas quais sistemas digitais, - agora dinâmicos, abertos e livres -, interoperem, e linguagens multimodais convirjam interativamente e online.

\begin{abstract}
As competências e as habilidades humanas, bem como as crenças estáveis culturalmente, condicionam olhares e o que é possível, aos olhos e mentes, perceberem nos códigos de comunicação. Por outro lado, as informações elaboradas como estruturas sistêmicas e complexidades informacionais criam dinâmicas. Estas implicam na mutualidade entre os sujeitos e os ambientes de informação, na qual as emergências podem criar novas conformações representacionais e de apresentação da informação (JORENTE, 2017).
\end{abstract}

Se, a partir da pós-modernidade, a explosão informacional é um desafio aos ambientes museais tradicionais e digitais, de acordo com as preconizações do paradigma pós custorial, este desafio será enfrentado por meio de uma visão de uma complexidade na qual os sistemas dinâmicos e colaborativos necessitam da disciplinaridade, das metodologias e das estratégias do DI, previstas em CD, para a criação e organização de ambientes interoperáveis por meio de convergências de linguagens para produção, armazenamento, recuperação e disseminação de informações na Web 2.0 ou colaborativa, facilitando interações e emergências sistêmicas. Na Web 2.0 ou Web Social (FUMERO, 2007), o MP desenvolve uma CD colaborativa devido a estratégias de um DI top-down e bottom-up, sistema em que tradicionais e novos agentes informacionais podem atuar como praticantes do DI (HORN, 1999). Destaca-se que, a partir de um design pré-definido em CD, histórias de vida emergem no sistema como objetos digitais ou acervo do MP, e que seu formato pode adquirir natureza multimodal (texto, audio, imagem, vídeo).

Em Design da Informação, linguagens convergentes e complexidade na rede social e ambiente digital do Facebook, (Autor, 2014) apresenta-se um estudo sobre o Design de Convergência daquele sistema, então com 500 milhões de usuários e com taxa de cerca de 100 milhões de novos usuários a cada 6 meses. Foram considerados no ambiente do Facebook dois tipos de convergência. $O$ primeiro tipo converge as que se apresentam na estrutura da interface de interação, enquanto o segundo diz respeito as que se situam em outras camadas estruturais e super estruturais. Estas ultimas podem estar também situadas nas relações entre os internautas e o ambiente, impalpáveis e culturais. O seu entendimento conjunto é necessário para pensar as mudanças culturais advindas de ambientes com design convergente a partir da hibridização midiática e da hibridização sujeito e mídias que se tramam e criam emergências sistêmicas. "Tendo em vista tais emergências, nossa percepção é do surgimento de uma progressiva reequilibração do sistema convergido por formações culturais metamidiáticas, ou seja, resultantes da confluência das mídias e de suas linguagens, porém delas já independentes, autoportantes" (AUTOR, 2014).

A partir da reelaboração dos sistemas, propõe-se um estudo das disciplinas que poderão levar a um uso consciente do meio digital, a um melhor relacionamento humano, a um melhor conhecimento de nós mesmos e do mundo. "O design pode ser aprendido como disciplina, linguagem, tecnologia e forma de reação aos nossos limites. Pode também ser associado TIC de maneira estratégica para nossa sobrevivência como espécie" (AUTOR, 2014). Contextualmente, adota-se, ainda, a proposição da CD como uma tecnologia que prevê convergências de linguagens em todas as camadas do sistema, como o Design de Convergência, com o objetivo de promover não apenas registro, indexação e armazenamento de histórias de vida, mas acesso e a recuperação da informação.

Leva-se, ainda, em consideração, o estudo de Herzog (2014) que propõe o uso do recurso indexação facetada para que entidades rotuladas possam conectar-se a outras histórias e suas entidades em coleções de histórias de vida no Museu. Entidades, portanto, vinculam-se e gravitam em torno de cada história de vida no desenho conceitual do sistema dinâmico, planejado em CD.

Em tal sistema memorial, uma determinada história pode, ou não, estar hibridizada em linguagens (multimodal), como imagens e audiovisuais e, pertencer ou não a um projeto ou coleção, mas será sempre acessada por meio de busca por termo indexado pelos internautas (folksonomia) à taxonomia pré-existente, emergência sistêmica prevista top-down para acolher protagonismos bottom-up dos que interagem com o ambiente. Neste modelo, conceitos e técnicas de áreas "aparentemente desconectadas: metodologias de indexação, construção de taxonomias, folksonomias, visualização de dados e Design de Interação são integrados em um processo unificado que vai desde a coleta e indexação dos depoimentos até sua visualização e interação." (HERZOG, 2014). 
Destaca-se que a aparente desconexão se deve por vícios de olhar contaminados pelo cartesianismo linear. Entretanto, existe uma conexão entre níveis diferentes de sistemas que, pensados pelo viés da complexidade, provocam as emergências das quais podem surgir inúmeras e, por vezes, surpreendentes possibilidades e propriedades.

Em consonância, Johnson, autor de Emergência: a vida integrada de formigas, cérebros, cidades e softwares (2003) salienta que, nas últimas décadas, estudos científicos sobre sistemas abertos e dinâmicos passam a ser adotados em práticas comerciais, de lojas online a sites na Web 2.0, por exemplo, que se utilizam de ambientes digitais com poder de auto-organização. Em seu livro, o autor avalia o programa Simcity, de Will Wrigth, dos anos noventa, como uma nova fase no desenvolvimento da história da auto-organização, uma vez que o comportamento emergente deixou de ser apenas objeto de estudo em laboratório e passou a ser um constructo interativo, popular e de massas

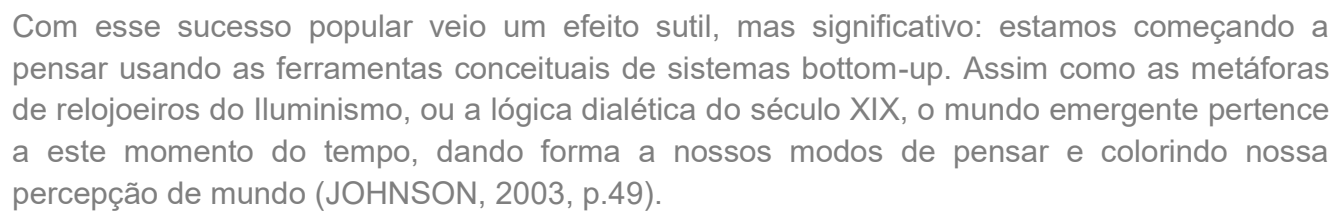

$\mathrm{Na}$ perspectiva disciplinar do DI, considera-se, pois, que a compreensão do princípio da complexidade dos sistemas dinâmicos e auto- organizáveis, ainda a ser explorado como método na $\mathrm{Cl}$, será o salto quântico necessário a novas formas de comunicação entre os agentes da informação, pois novos sujeitos protagonistas do século XXI exigem dos profissionais da informação, entre eles o cientista da informação, novas competências para efetivas mudanças paradigmáticas.

Nesta direção, acrescenta-se a opção do MP de desenvolver, em 2016, Design Responsivo, ao invés da possível migração da plataforma Apache Shiro 1.0 para a Apache Shiro 2.0, privilegiando o acesso e consequente ampliação da comunicação top-bottom para diferentes telas. Segundo o historiador Lucas Lara, pesquisador e profissional da informação da instituição, sem uma rápida implantação deste recurso, o MP teria corrido o risco de acelerar a queda dos números de acesso. Mantendo-se na mesma versão 1.0 do sistema, a partir de maio de 2016, o MP trabalha atualmente com novo escritório de projetos em tecnologia da informação para o gerenciamento da sua plataforma, a Hands $\mathrm{On}^{9}$, que tem realizado manutenções e consultorias sobre métricas do Portal e sobre o uso Google Adwords entre outros serviços, como correção de bugs e o desenvolvimento de landing pages ${ }^{10}$ (recurso tecnológico a ser explorado em futuros artigos).

\section{Considerações}

No âmbito da $\mathrm{Cl}$, o DI é o recurso que permite aos profissionais da informação prever, de modo top-down, emergências bottom-up em ambiência digital, oportunizando novas reflexões sobre o musealizar como um ato político e ético que requer protagonismos de novos agentes informacionais, profissionais ou não.

Neste contexto, o estudo entende ser esta a importância do DI no trabalho do cientista da informação, uma vez que a Curadoria Digital de sistemas interativos e colaborativos na Web 2.0 propõe, como um desafio aos especialistas da área e aos demais atores da informação, uma capacitação para os meios digitais que seja facilitadora da criação de uma cultura de compartilhamento da informação em ambiência digital.

Tomando o DI como uma área científica, destaca-se que seus recursos técnicos e metodológicos, quando aplicados, traduzem matrizes hibridas de linguagens para o ambiente digital e seus significados que, em nosso contexto, remetem a fatos museais (RÚSSIO, 2010) reconhecíveis (tipos, padrões) e recuperáveis, designados e previstos em Curadoria Digital. A eficiente conjunção entre significado e significante resultará, em meio digito virtual, no acesso e reconhecimento de signos protocolares em interface de interação com internautas: quanto mais eficiente a representação, maior o valor do objeto representado.

Quanto à custódia ampliada, na Web 2.0, também conhecida como Social e Colaborativa, as TIC potencializam, no MP, emergências constantes de fatos museais online de visitantes que passam a se identificar (ao postarem suas memórias) tanto como sujeito protagonista quanto como objeto identitário, ao mesmo tempo. Assim, adentra-se um ambiente museal que, não apenas coloca em chave a relação sujeito-objeto, mas também permite (e estimula) que sujeitos se musealizem com o propósito de virem a ser fonte de informação para pesquisas futuras, promovendo a percepção e o reconhecimento de afinidades e a construção de identidades.

Assim, o valor do objeto ou fato museal do MP, tratado como seu acervo, é sua própria representação coordenada pelo DI, que cumpre a complexa tarefa de tradução interssemiótica (PLAZA, 2003) de linguagens, 
vertendo-as em informação ressignificadas na Web 2.0, transcriando (CAMPOS, 2010) zeros e uns. No estudo, considera-se o DI não apenas uma disciplina científica e metodológica, mas uma arte aplicada; e, neste caso, aplicada à reconstituição do sistema de signos em que estão inseridas as informações. No contexto do MP, por se tratar de simulacro, o seu DI tem o importante papel de traduzir e comunicar protocolos reconhecíveis aos grupos humanos.

A informação entendida como coisa (BUCKLAND, 1991), ou evidência tangível, cumpre uma função mnemônica para uma construção mental que reconheça elementos padrão, local e globalmente. Se a evocação da memória humana como representação mental passa a ser recuperada na web 2.0, é justamente pelo seu DI como recurso mnemotécnico ${ }^{11}$. No caso do MP, o papel do DI, a partir de sua superestrutura até interfaces de interação, é propiciar trocas de informações identitárias de modo semelhante ao feromônio na comunicação das formigas (JOHSON, 2001), criando dinâmicas que implicam na mutualidade entre os sujeitos e os ambientes de informação, na qual as emergências podem criar novas conformações representacionais e de apresentação da informação (JORENTE, 2017).

Em última instância, quanto mais eficiente o simulacro, ou coerência entre significado (conteúdo informacional, evidências, fatos, coisas do universo social) e significante - DI, forma, suporte artístico-científico -, maior e mais fácil será a compreensão dos signos computacionais traduzidos, o que facilitará a interatividade e a colaboração no ambiente.

Quanto ao seu papel, o profissional da informação, convergido como designer hibridizado deve, além de refletir conceitualmente sobre sua ação, dominar a ciência e arte deste tipo de retórica (YATES, 2007) contemporânea para comunicar, muitas vezes, o ainda indizível, tal qual o feromônio das formigas, ou o DNA de nossas células (JOHNSON, 2001), emulando, ou, simulando um sentido para a vida. 


\section{Referências}

ARAÚJO, C. A. A. Arquivologia, Biblioteconomia, Museologia e ciência da informação: o diálogo possível. Brasília: Briquet de Lemos, 2014. São Paulo: Associação Brasileira de Profissionais da Informação (ABRAINFO), 2014.

BRUNO, Maria Cristina O. (coord.). Waldisa Rússio Camargo Guarniéri: textos e contextos de uma trajetória profissional. 2 v. São Paulo: Pinacoteca do Estado / Secretaria de Estado da Cultura / Comitê Brasileiro do Conselho Internacional de Museus, 2010

BUFREM, L. S. Configurações da pesquisa em ciência da informação. DataGramaZero, v. 14, n. 6, 2013.

BUCKLAND, M. K. Information as thing. Journal of the American Society for Information Science (JASIS), v.45, n.5, p.351360, 1991.

CAPURRO, R. Epistemologia e Ciência da informação. In: V ENCONTRO NACIONAL DE PESQUISA EM CIÊNCIA DA INFORMAÇÃO, 5., Belo Horizonte, 2003. Anais... Belo Horizonte: Escola de Ciência da informação da UFMG, 2003. 1 cd-rom.

CAMPOS, H. de. Metalinguagem e outras metas: ensaios de teoria e crítica literária. São Paulo: Perspectiva, 2010.

FUMERO, A. M. Contexto sociotécnico. In: FUMERO, A.; ROCA, G. Redes Web 2.0. Fundación Orange, 2007. p. 8-64. Disponível em: <http://www.oei.es/historico/noticias/spip.php?article762>. Acesso em: 28 dez. 2017.

HENRIQUES, R. Memória, Museologia e virtualidade: um estudo sobre o Museu da Pessoa. 2004. 182 f. Dissertação (Mestrado em Museologia) - Departamento de Arquitectura, Urbanismo e Geografia, Universidade Lusófona de Humanidades e Tecnologias, Lisboa, 2004. Disponível em: <https://pesquisafacomufjf.files.wordpress.com/2013/06/memc3b3riamuseologia-e-virtualidade-um-estudo-sobre-o-museu-da-pessoa.pdf>. Acesso em: 22 mar. 2017.

HENRIQUES, P.R. Conexões além-mar. In: História Falada: memória, rede e mudança social. Coordenadores Karen Worcman e Jesus Vasquez Pereira. São Paulo: SESC SP: Museu da Pessoa: Imprensa Oficial do Estado de São Paulo, 2005.

HERZOG, P. Sistema para indexação e visualização de depoimentos de história oral - 0 caso do Museu da Pessoa. 2014. 90f. Dissertação (Mestrado em Design - Escola Superior de Desenho Industrial, Universidade do Estado do Rio de Janeiro, Rio de Janeiro, 2014

HORN, R. Information Design: Emergence of a New Profession. In: R. Jacobson (Org.). Information Design. Cambridge, Massachusetts: The MIT Press, 1999. p. 15-33.

JACOBSON, R. Information Design. Cambridge, Massachusetts: The MIT Press, 1999.

JOHNSON, S. Cultura de Interface. Rio de Janeiro: Jorge Zahar, 2001. Disponível em: $<$ http://formatandoconhecimento. wikispaces.com/file/view/Steven+Johnson+-+Cultura+da+interfac.pdf> Acesso em: 22 mar. 2017.

JOHNSON, S. Emergência: a vida integrada de formigas, cérebros, cidades e softwares. Rio de Janeiro: Jorge Zahar Ed., 2003.

JORENTE, M. J. V. Impacto das tecnologias de informação e comunicação: cultura digital e mudanças sócio-culturais. Informação \& Sociedade: Estudos, v. 22, n. 1, 2012. Disponível em: <http://hdl. handle.net/20.500.11959/brapci/92767>.

JORENTE, M. J. V. Design da informação, linguagens convergentes e complexidade na rede social e ambiente digital do facebook. Informação \& Tecnologia, v. 1, n. 1, p. 116-129, 2014. Disponível em: <http://hdl. handle.net/20.500.11959/brapci/40805>.

JORENTE, M. J. V.; PADUA, M. C.; NAKANO, N.; KAHN, K.; BATISTA, L. S. Avaliação da arquitetura e design da informação de ambientes e-health: um projeto de colaboração internacional e interdisciplinar. Pesquisa Brasileira em Ciência da Informação e Biblioteconomia, v. 12, n. 2, 2017. DOI: 10.22478/ufpb.1981-0695.2017v12n2.37063.

KAHN, K.; JORENTE, M. J. V. O papel do design da informação na curadoria digital do museu da pessoa. InCID: Revista de Ciência da Informação e Documentação, v. 7 n. 2, n. 2, p. 23-39, 2016. DOI: 10.11606/issn.2178-2075.v7i2p23-39.

MENSCH, P. V. O objeto de estudo da museologia. Tradução de Débora Bolsanello e Vânia Dolores Estevam de Oliveira. Rio de Janeiro: UNIRIO/UGF, 1994. (Pretextos museológicos, 1).

MINSKY, M. The Society of Mind. Nova York:Touchstone, 1985. 
MORIN, E. O pensamento complexo, um pensamento que pensa. In: MORIN, E.; MOIGNE, J. L. A inteligência da complexidade. 3.ed. Uberaba: Peirópolis, 2000. 268p.; p.197-213.

PEREIRA, J.V.; WORCMAN, K. História Falada: memória, rede e mudança social. Coordenadores Karen Worcman e Jesus Vasquez Pereira. São Paulo: SESC SP: Museu da Pessoa: Imprensa Oficial do Estado de São Paulo, 2006.

PLAZA, J. Tradução Intersemiótica. São Paulo: Perspectiva, 2003.

RIBEIRO, F. Da mediação passiva à Mediação Pós-Custodial: o papel da Ciência da Informação na sociedade em rede. Informação \& Sociedade, João Pessoa, v. 20, n. 1, p. 63-70, jan./abr. $2010 . \quad$ Disponível em: $<$ <ttp://www.ies.ufpb.br/ojs2/index.php/ies/article/view/4440/342>. Acesso em: 22 mar.2017.

RÚSSIO, W. A interdisciplinaridade em Museologia (1981). In: BRUNO, M. O. (Org.). Waldisa Rússio Camargo Guarnieri: textos e contextos de uma trajetória profissional. São Paulo: Pinacoteca do Estado: Secretaria de Estado da Cultura: Comitê Brasileiro do Conselho Internacional de Museus, 2010. v. 1. p. 123-126.

SAYÃO, L.F., SALES, L.F. Curadoria Digital: um novo patamar para preservação de dados digitais de pesquisa. Inf. \& Soc.:Est., João Pessoa, v.22, n.3, p. 179-191, set./dez. 2012. Disponível em: <http://www.ies.ufpb.br/ojs/index.php/ies/article/view/12224/8586.>. Acesso: 17 out. 2017.

SEVCENKO, N. A palavra e o reencantamento do mundo.In: História Falada: memória, rede e mudança social. Coordenadores Karen Worcman e Jesus Vasquez Pereira. São Paulo: SESC SP: Museu da Pessoa: Imprensa Oficial do Estado de São Paulo, 2005

THOMPSON, P. A Voz do Passado: história oral [The Voice of the Past: Oral History]. Rio de Janeiro, Paz e Terra, 1992.

WAGENSBERG, J. O Museu 'total', uma ferramenta para a mudança social. In: Congresso mundial de centros de ciência, 4., 2005, Rio de Janeiro. Anais... Rio de Janeiro: Fiocruz, 2005. Disponível em: <http://www. museudavida.fiocruz.br/4scwc/Texto\%20Provocativo\%20-\%20Jorge\%20Wagensberg.pdf> Acesso em: 22 mar. 2017.

YATES, Francis A. A arte da Memória. Campinas: Editora da UNICAMP, 2007.

\section{Dados das autoras}

\section{Maria José Vicentini Jorente}

Livre Docente em Cultura Digital e Informação Pós Custodiada em Redes de Colaboração. Doutora pelo Programa de Pós-Graduação em Ciência da Informação da Universidade Estadual Paulista Júlio de Mesquita Filho (Unesp). Especialista em Design de Produto. Licenciada em Artes pela Fundação Armando Álvares Penteado (FAAP) e em Letras pela Universidade de São Paulo (USP). Professora Adjunta em Regime de Dedicação Integral à Docência e à Pesquisa da Universidade Estadual Paulista Júlio de Mesquita Filho, Faculdade de Filosofia e Ciências - FFC - Campus de Marília, Departamento de Ciência da Informação. Docente dos cursos de graduação em Arquivologia e Biblioteconomia e dos cursos de mestrado acadêmico e doutorado em Ciência da Informação da Unesp. Investigadora nas áreas de Informação e Tecnologia, Curadoria Digital, Mídias, Intersemiótica, Design de Informação.Membro dos conselhos dos cursos de Biblioteconomia e de Arquivologia e do Conselho de Pós-Graduação em Ciência da Informação da UNESP de Marília. Membro do Grupo Novas Tecnologias em Informação (GPNTI) da UNESP. Membro de comissão científica de agências de fomento e periódicos na área da Ciencia da Informação.

mjjorente@marilia.unesp.br

\section{Karen Kahn}

Graduada em Letras - Português/Hebraico pela FFLCH da Universidade de São Paulo (USP); licenciada pela Faculdade de Educação/FE da mesma Universidade; pós-graduada em Jornalismo Literário pela ABJL (Lato Sensu) e mestre em Ciência da Informação (CAPES 6) na Universidade Estadual Paulista Julio de Mesquita Filho (UNESP- Campus de Marília). Sua pesquisa envolve o papel do Design da Informação na Curadoria Digital de Sistemas Memoriais, ambiências digitais como o Museu da Pessoa. Desde 2015, pertence ao Grupo de 
Pesquisa Novas Tecnologias em Informação (GPNTI) e ao Laboratório de Design e Recuperação da Informação (LADRI). Coordenou Núcleos de Ação Educativa de museus- casas geridos pela Secretaria do Estado da Cultura (SEC), como o a Casa das Rosas e o e o museu Casa Guilherme de Almeida; e coordena o Projeto Escrevivendo - oficinas de escrita e leitura para o cotidiano em museus e bibliotecas como a Biblioteca de São Paulo (Carandiru), a Biblioteca Temática de Poesia Alceu Amoroso Lima e o Museu da Língua Portuguesa, entre outras instituições de informação e memoria na cidade de São Paulo. Em 2016, coordenou o Projeto de oficinas de leitura e escrita Nossas Letras no SESC Belenzinho e, em 2017, o Projeto Escrevivendo no SESC de Santos. Entre 2014 e 2018, atuou como coordenadora cultural da Casa da Cultura Carlos e Diva Pinho. karenkipnis@yahoo.com.br

Received - Recibido: 2017-05-13

Accepted - Aceptado: 2018-12-14

\footnotetext{
${ }^{1}$ Para aprofundamento do tema born digital, sugere-se, como Ribeiro (2010), a leitura de PALFREY, J.; GASSER, U. Born digital: understanding the first generation of digital natives. New York: Basic Books, 2008.

${ }^{2}$ Link para o Museu da Pessoa. Disponível em: <http://www. museudapessoa.net/pt/home>. Acesso em: 22 mar.2017.

${ }^{3}$ Link para Missão e Objetivos do MP: <https://www.cursosmuseudapessoa. net/sobre-o-museu-da-pessoa>. Acesso em: 28 dez. 2017.
}

${ }^{4}$ Tecnologia Social da Memória: para comunidades, movimentos sociais e instituições registrarem suas histórias. Museu da Pessoa, São Paulo. 2009. 51p. Disponível em: $<$ http://www.museudapessoa.net/public/editor/livro tecnologia social da memoria.pdf> Acesso em: 22 mar. 2017.

${ }^{5}$ Link para a publicação História Falada: <http://www.museudapessoa.net/pt/entenda/portfolio/publicacoes/metodologia/historia-falada-2005>. Acesso em: 22 mar.2017.

${ }^{6}$ Link para Conceitos-chave de Museologia:

$<$ http://icom.museum/fileadmin/user upload/pdf/Key Concepts of Museology/Conceitos-ChavedeMuseologia pt.pdf $>$ Acesso em: 22 mar. 2017.

${ }^{7}$ O Museu da Pessoa sustenta-se em plataforma Apache Shiro 1.0, ainda em fase beta, desenvolvido em framework Code Igniter 17 (PHP/MySQL), conforme Herzog (2014).

${ }^{8}$ Pedro Herzog é diretor do Plano B, escritório de design responsável pela Curadoria Digital da plataforma do Museu da Pessoa até 2016. Link para Plano B: <http://www. plano-b.com.br/>. Acesso em: 22 mar.2017.

${ }^{9}$ Link para Hands on, escritório de projetos-tecnologia de informação que oferece suporte e manutenção de websites. Disponível em: <http://www.handson-ti.com.br>. Acesso em: 22 mar. 2017.

${ }^{10}$ Link para o Blog Seomaster. Disponível em: <http://www.seomaster.com.br/blog/o-que-e-landing-page>. Acesso em: 22 mar. 2017.

11 O termo Mnemotécnica, segundo a enciclopédia livre Wikipédia, apesar das suas raízes gregas, é de uso moderno, com origem no século XIX, e tornou-se sinónimo do termo "ars memoriae", Arte da Memória, usado na antiguidade clássica. A

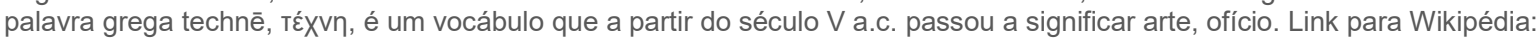
<https://pt.wikipedia.org/wiki/Mnemot\%C3\%A9cnica>. Acesso em: 22 mar.2017.

\section{$((c))$ EY}

This work is licensed under a Creative Commons Attribution 4.0

United States License.

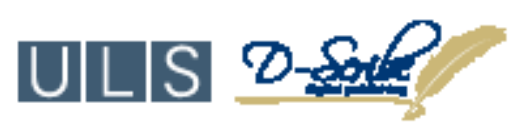

This journal is published by the University Library System of the University of Pittsburgh as part of its D-Scribe Digital Publishing Program and is cosponsored by the University of Pittsburgh Press. 